\title{
A Narrative Inquiry into a Newcomer School Principal's Professional Development for ELLs
}

\author{
Liping $\mathrm{Wei}^{1}$ \\ ${ }^{1}$ School of Education, Health Professions, \& Human Development, University of Houston-Victoria, TX, USA \\ Correspondence: Liping Wei, School of Education, Health Professions, \& Human Development, University of \\ Houston-Victoria, TX, USA.
}

Received: October 8, 2020

Accepted: November 12, 2020

Online Published: November 20, 2020

doi: $10.5539 /$ elt.v13n12p57

URL: https://doi.org/10.5539/elt.v13n12p57

\begin{abstract}
This paper employs narrative inquiry (Clandinin \& Connelly, 2000) as the methodology to uncover a school principal's experiences and perceptions related to ELL teacher professional development. It recognizes educators' personal practical knowledge as the greatest driving force in their professional growth. Through reflecting on her professional development experiences and narrating her personal practical knowledge in action, this study has provided some practical considerations in designing and enacting ELL teacher professional development. More often than not, teacher professional development focuses on the "best practices" and "research-based programs," but provides little input from the recipients about their experiences and perspectives. This study strives to break this prevalent model of professional development by gearing towards how an educator/administrator perceives the problems in teacher professional development for ELLs and how to best address their problems. It is hopeful that this study will shed important light on how to construct positive professional development that benefits teachers and ELL students both theoretically and practically.
\end{abstract}

Keywords: narrative inquiry, professional development, personal practical knowledge, problems, practical considerations

\section{Introduction}

The dramatic increase of non-English-native-speaking students is probably one of the most significant shifts in the demographics of U.S. schools today. Needless to say, the rapid growth of ELL students and the widening achievement gap are calling for quality public school teachers more than ever. However, a study conducted by Texas A\&M University (2007) showed that $40 \%$ of Texas school superintendents reported a shortage of certified teachers in ESL. Texas Education Agency (2020) listed ESL as one of the critical shortage areas for the 2020-2021 school year. Providing a high-quality education for ELL students has become a priority in education at the national level. ELL teacher professional development is among the most salient and pressing topics in educational research nowadays.

Professional development is an essential aspect of the educational life of teachers. Guskev (2000) defined it as "processes and activities designed to enhance the professional knowledge, skills, and attitudes of educators so that they might, in turn, improve the learning of students" (p. 16). This paper intends to employ narrative inquiry (Clandinin \& Connelly, 2000) as the methodology to uncover a school principal's experiences and perceptions related to ELL teacher professional development. To engage ELL teachers in professional growth, it is critical to understand how teachers' personal experiences and perspectives are interwoven with their teaching philosophy and practices. It is hoped that this research will bring to the forefront how educators' personal practical knowledge serves as the greatest driving force in their professional growth.

\section{Literature Review}

Effective professional development is key to improving teacher performance, which transforms to better student performance (Short, 2013). It is echoed by Smith (2014) that teachers can most likely help prepare ELLs who are academically successful when they understand the theory- and research-based foundations of ELL instruction and use this knowledge to make informed decisions that work best for their ELLs. Among the studies on ELL teacher professional development, some have emphasized the significance of theory (Choi \& Morrison, 2013; 
Mensh, 2013); some have described specific professional development programs for ELL teachers (Clair \& Adger, 2010; Tarone \& Allright, 2005; Walqui, 2006).

Franco-Fuenmayor (2013) used a mixed-methods approach to study dual language, bilingual, and ESL teachers' knowledge, professional development experiences, and perceptions about second language programs in Texas. Maxwell (2011) tried to address the problems in ESL instruction by introducing a professional development program that incorporates the feedback from ELLs. Echevarria, Short, and Powers (2006) viewed Sheltered Instruction and Sheltered Instruction Observation Protocol (SIOP) as the basis of professional development for teachers of ELLs. Teachers were trained to incorporate specialized strategies and techniques of the SIOP model in an attempt to increase language development and academic achievement of ELLs.

Some studies revolved around what influence professional development has exerted on teachers. Teemant (2014) conducted a longitudinal mixed-methods study to investigate the efficacy and sustainability of instructional coaching outcomes among urban elementary teachers. Choi and Morrison (2013) explored the change processes in teacher perceptions and classroom practice in a five-year hybrid professional development program for teachers of ELLs in Oregon. Ramirez, Gonzales-Galindo, and Roy (2016) documented the change of a cohort of pre-service teachers in the aspects of teacher consciousness, language matters, and multicultural resources during their one-year residency. This multi-case study captured teacher doubts, thoughts, and changes.

A series of research about Sheltered Instruction Observation for Protocol (SIOP) has been carried out by Short and other researchers (Short, 2013; Short, Echevarria, \& Richards-Tutor, 2011). The research studies following this line have informed us on how to use SIOP model to make content comprehensible to ELLs. Based on SIOP, Honigsfeld and Cohan (2008) discussed the combination of two professional development strategies-lesson study and SIOP, which gave teachers new tools for improving instruction for ELLs in mainstream classrooms.

Social context is also brought into consideration of ELL teacher professional development. Zehr (2011) reported a school-district-wide teacher training whose philosophy is that language is learned best in a social context, so lessons should be planned to engage students in structured social interactions about the academic concepts they are learning. Coleman and Goldenberg (2010) also identified the integration of social context as an effective strategy that promotes the oral and academic language development of ELLs.

Collaboration is witnessed in different forms of ELL teacher development. Beninghof and Leensvaart (2016) described a professional development program teachers in an elementary school in Colorado received that allows them to partner with ESL teachers to provide language and content instruction simultaneously. This program quickly revealed itself as a most effective way to maximize teacher professional development and students' growth. DelliCarpini and Gulla (2009) discussed the collaborative practice between English Language Arts (ELA) teachers and ELL teachers, through which, ELLs were able to achieve language-driven content objectives in ESL classroom as well as content-driven language objectives in ELA classroom. Molle (2013) studied discourse analysis of interaction among K-12 teachers and administrators in a professional development program designed for educators working with ELLs and provided an empirical illustration of how recommendations in the literature about professional development for educators of ELLs can be put into practice.

A study worth special noting is the one by Welsh and Newman (2010) that also uses narrative inquiry in describing the changes of an $8^{\text {th }}$-grade science teacher in an ELL sheltered science class before and after receiving professional development. Through examining how the science teacher transformed from content to content-ESL teacher, the dialogical nature of this research provided content teachers with the tools they need to work more effectively with ELLs. Furthermore, the immediate feedback from the teachers gave teacher educators validation of their efforts and helped them to adjust to better meet the needs of ELL teachers.

\section{Methodology}

As described by Connelly and Clandinin (1990), narrative inquiry is "a study of the ways humans experience the world" (p. 2), grounded in the belief that stories are the best portal through which human experience is interpreted and made meaningful both individually and socially. Utilizing native inquiry, this study unpacks the experiences and perspectives of Ms. Monica, a public school principal, concerning professional development for ELLs. Her experiences and perspectives, as storied and restoried, will be unfolded through semi-structured interviews and informal conversations.

Ms. Monica is the Principal of a newcomer middle school in a large school district in Texas. She has a Bachelor's degree in Computer Science, a Master's degree in Educational Leadership, and is just starting her doctoral studies in Equity and Social Justice. She has been working in the same school district for 23 years, with the first 10 years as a teacher and then an assistant principal at a high school, and 13 years as the principal of this 
newcomer middle school. As the only newcomer school in this school district, it was created in 2001, and Ms. Monica has been its $2^{\text {nd }}$ principal since 2005 .

"Narrative inquiry is much more than the telling of stories" (Clandinin, Pushor, \& Orr, 2007, p. 21); it "need(s) to move to the retelling and reliving of stories, that is, to inquiry into stories" (p. 33). Three analytical tools - broadening, burrowing, storying and restorying (Connelly \& Clandinin, 1990) - will be used for "narratively cod (ing)" the field texts (Clandinin \& Connelly, 2000, p. 131) in their transition to research texts. Broadening occurs when the narratives are situated in a larger social, cultural, political, and historical context, e.g., educational policies, school climate, and teacher learning community. Burrowing allows me to gain an up-close examination of the participant's experiences and reveal the nuances of their stories. Additionally, storying and restorying bring to surface the breadth and depth of participant's perspectives that may change across contexts and over time. Taken together, the three interpretive devices will enable me to channel field texts into research texts that "grow out of the repeated asking of questions concerning meaning and significance" (Clandinin \& Connelly, 2000, p. 132).

Like other forms of social science research, narrative inquiry texts "require evidence, interpretive plausibility, and disciplined thought" (Connelly \& Clandinin, 2006, p. 485). This evidence, however, does not rely on criteria, such as validity, reliability, and generalizability, as in quantitative research. Instead, what a narrative inquirer seeks to establish is "not truth but truth-likeness or verisimilitude" (Bruner, 1985, p. 97), "a compound of coherence and pragmatic utility," as Bruner asserted (1996, p. 90). Lyons and LaBoskey (2002) also suggested that for narrative inquirers, "validity" rests on concrete examples of actual practices presented in enough detail so that the relevant community can judge the credibility and usefulness of the observations and the analysis of an inquiry. Significance, then, is rooted in believability and trustworthiness rather than the absolute consistency or authenticity of events. Therefore, the core of establishing the credibility of this research will lie in authenticity, resonance, and trustworthiness. Strategies, including triangulation, member checks, and peer debriefing, were applied to achieve these purposes.

\section{Ms. Monica's Experience with ELLs and ELL Professional Development}

Ms. Monica's 23 years in education have all centered around $2^{\text {nd }}$ language learners. Her students are from across the world and are highly diverse. To better reach out to students, she has been to Uganda, Kenya, Israel, etc. to learn what refugee life looks like, so she can better help her teachers to associate and understand where their students come from. As Ms. Monica said, "You have to truly understand their backgrounds to help them overcome the difficulties they are having and learn the language."

She asserted that she had got "a lot more professional development than many teachers have received, and received it multiple, multiple, multiple times" in her past two decades in education. For example, she has received SIOP training "in every different way." She has had 6 hours for each of the 8 components of SIOP and has got 6 hours of Component 1 three times already. She proudly claimed that she has received over 100 hours of SIOP training.

Every time I hear it, I learn something new. It's not like "Check that box. Oh, I've already done that training. I don't need to hear it anymore." When I have new teachers, and when my teachers are being trained, let me go in there and hear it again. Because I believe that if you are going to train teachers, then it's important for your teachers to see you in that same training. I'll look for what's something new I'll get or look at from a different perspective. (Ms. Monica)

Among the numerous professional development programs she has received for ELLs, she has had Kagan training, Marzano training, Ruby Payne training, training on students with interrupted formal education, training on listening, speaking, reading, and writing, to name just a few.

She provides professional development for the teachers on her campus every Thursday. "I teach them how to do work stations, how to do interactive workbook, how to effectively use the materials, different ways of checking for understanding, lesson delivery, various strategies they can use, etc.," she introduced. She even gives 4 to 6 hours of training on Saturdays if she sees some teachers need it. When asked about how she perceives the professional development programs provided by the school district, she first acknowledged the usefulness of some training the district offered, such as those on math manipulatives and interactive word walls. However, she continued to allude to two reasons why she prefers the professional development by her to that by the district. One reason is that as the only newcomer school in the district, not many professional development programs by the district are most suitable for them. The other reason is that the professional development by the district is optional and teachers sign up for the ones they "would like to" attend, whereas the weekly training by her is 
mandatory that every teacher "must" attend. She considers teachers' participation in professional development to be indispensable.

\section{What Professional Development Means to School Leaders}

The minute I stop learning, I think, is the minute I should step away from this job.

Ms. Monica

As a school principal, Ms. Monica is required to follow the school district appraisal and development system to evaluate all the teachers on her campus on an individual basis. This, according to her, is where professional development has benefited her most.

Telling them (teachers) "good job, way to go, or keep on doing it" doesn't really help them perform better. This appraisal system requires us to say "That is a great lesson. I saw you do $\mathrm{x}, \mathrm{y}$, and z." My feedback would be like "I want you to get better in reading comprehension, differentiation, etc., and here are the strategies to help you address it. Or refer to chapter 7 of this particular book where it discusses this specific problem." (Ms. Monica)

Offering teachers concrete feedback on all areas of teaching requires Ms. Monica to constantly learn. As she commented, "Professional development is very helpful. Try doing this. Try doing that. I'm constantly receiving professional development to coach my teachers." She took pride in a large collection of books and other resources displayed in her office, which is from all the professional development she has received. She likes to absorb new information and experiment to see what works best and tweak it to make it fit for the teachers on her campus. In her own terms, what she has obtained is "just a collection of different models that I then use to tailor to what I want my teachers to know."

It is evident that professional development has been instrumental in helping her to supervise and support her teachers.

I never stop learning, esp. working with a highly diverse population of kids. I try to receive professional development as often as I can. The minute I stop learning, I think, is the minute I should step away from this job. As an educational leader, you got to keep up learning, so that your teachers can continue to grow, and your kids can continue to grow. It never ends. Ultimately, in my opinion, that's what the role of a principal is. (Ms. Monica)

\section{Tailoring Professional Development Programs to Specific Groups of ELLs}

You got to ask "Where are they." That's where we are and we have to take it from there.

Ms. Monica

Ms. Monica recalled an incidence with a newcomer student that has made an indelible mark in her memory and always reminded her to never forget the importance of starting from students' needs. It was that student's first day at the school, and Ms. Monica gave him a pencil and asked him to write his name in his native language. This 14-year-old boy clenched the pencil with the pencil point up in the air, kept making the sound, "Huh? Huh? ..." Ms. Monica patiently explained with her body movement, signaling him to write down his name with the pencil. Whatever ways she tried, the boy was still at a loss, looking at her and the pencil blankly. She finally found out that the boy did not know how to hold a pencil because he had never seen a pencil or a book in his prior life in his home country. Needless to say, he did not have any schooling experience or literacy skills in his native language.

This experience is so striking to her, which prompted her to start questioning some of her presumptions. As Ms. Monica observed, "We have always assumed middle school students always have the opportunity to go to school, and that's not true. You got to ask 'Where are they.' That's where we are and we have to take it from there." For this particular student, Ms. Monica instructed his classroom teacher to make a plan that started by teaching the student how to hold a pencil, open a book, and write his name like what a 2- year-old would learn, though he is 14 years old already.

ELLs are vastly different from each other, and their needs vary accordingly. Therefore, as Ms. Monica remarked, "Whenever you work with ELLs, you can't just take a program, and then open it up, and say 'Okay, now I've had a training, I'm gonna use it and teach it to the kids.' This may be a great program, but not necessarily work for each and every of your ELLs." To meet the needs of all the students, it is essential to differentiate instruction. Ms. Monica made the following statement regarding differentiated instruction, 
The way we were used to teaching a class of 20 only meets the middle. You have kids that are too easy, and you have kids that are too high. So when you are only meeting the middle, you are not reaching all other kids. You need to learn to differentiate. This table is learning letters. This table is learning blends. This table is learning spelling ... You got to meet all your students at their levels. When you look into a classroom and walk around, you see everybody is engaged, doing something that is just enough hard for him or her, not too hard, not too easy. That's what we need. (Ms. Monica)

For that to happen, she added, "this means you have to be able to have a variety of tools, your toolbox, so that you can pull it whenever it's needed."

\section{The Importance of Teaching Reading to ELLs}

We, as a society, need to think about how to better prepare our middle school and high school teachers to teach ELLs how to read.

Ms. Monica

It is distressing to Ms. Monica that many long-term ELLs are at far below grade level in reading and writing abilities.

They've been in America for a long time, but no one has taught them how to read. That's why we have so many long-term ELLs who never got out of ESL. Every year they are beginning, beginning, and beginning. They can't ever get out of beginning, because they are never taught how to read. (Ms. Monica)

These students may be at the advanced level in reading and listening, but their reading and writing may be still at the beginning level. Chomsky (1965)'s distinction between "competence" and "performance" has important implications in this regard. "Competence" is a language user's underlying knowledge about the system of rules, whereas "performance" is the actual use of language in concrete situations. A student's "performance" is not always a good predictor of his/her "competence." This is demonstrated clearly in long-term ELLs, whose "performance" usually exceeds their "competence."

According to second language acquisition (SLA) theories, similar to how the first language is acquired, people acquire their oral abilities of a second language when they spend a considerable amount of time being immersed in that language. The theoretical premise underlying is that comprehension precedes production, that is, listening comprehension is developed before students can speak the language. Listening and speaking are the two modalities language learners learn the quickest, which precede reading and writing. ELLs eventually will learn how to speak the language. However, if no one teaches them how to read, they will not be able to read and write in this language, and that becomes an enormous hindrance to their academic achievement on the STAAR test.

Ms. Monica believes that teaching ELLs to read is key to the education of ELLs. Being able to read is the basis of not only learning a second language and its culture but also the basis of learning academic content and developing critical thinking. Not until ELLs learn to read will they be able to read to learn. It is Ms. Monica's philosophy that in teaching them to read, phonics-letters and sounds, should be where to start with. She maintains that "That (teaching ELLs phonics) should be the bulk of our ESL professional development." However, she pointed out that,

It is the foundation piece that for whatever reason people feel it's a waste of time, and we don't need to teach that. We need to teach main ideas, context clues, inferencing, and sequencing. Yes, that's important. But if you don't know how to read to get that information, that doesn't even matter. So I feel like we missed the bone of teachers' professional development if you are not getting down to this area. (Ms. Monica)

To some degree, she attributes this phenomenon to the STAAR test that teachers are held responsible for.

Most schools focus on STAAR test. The STAAR test is what we have to teach because we got to teach these TEKS to pass the test. That's the problem state wise. We got to somehow someway teach in professional development that it's OK to teach kids letters, sounds, and the alphabet when they are 13 years old. It's okay to do that, and it's essential to do that. (Ms. Monica)

Another counterforce to teaching middle school ELLs phonics, as Ms. Monica analyzed, comes from middle school teachers.

Middle school teachers think this is an elementary problem. That's not my problem. Elementary teachers need to teach them how to read. They are experienced in teaching them how to read. I'm in middle school. I teach them middle school stuff. That's what I do. But if the ELLs didn't get the 
primary (letters and sounds), you have to teach them the primary. We can't expect the elementary teachers to do that. They (students) weren't here for elementary. You can't just blame it on them. You just need to pick it up yourself, and our middle school teachers don't know how to do that. (Ms. Monica)

Her comments brought to surface two issues that exist in middle school teachers working with ELLs. One is a misconception that it may not be the responsibility of middle school teachers to teach ELLs letters and sounds. The other is the feeling of inadequacy of middle school teachers in teaching the basics of reading. Teaching such a foundational piece to ELLs in middle schools involves greater complexities than that in early childhood. Lack of age-appropriate materials is a challenge, which Ms. Monica explained aptly as follows,

When you teach early literacy_-sounds, letters, and blends, the 1st thing you think of is Barney. But when you have 13 years old, listening to Barney is so inappropriate. Putting a 14-years old with childish stuff, they'll look at you and say, 'I'm not stupid. I don't know English, but I'm not dumb. Why are you telling me to listen to Barney and put me on PBS to see Sesame Street? Seriously? I'm 14 years old, and I don't like a puppet to talk to me." (Ms. Monica)

These remarks bring home the need to be respectful of the materials teachers use with ELLs. On the one hand, the materials should be adapted to the English proficiency of the students. On the other hand, they should also be age-appropriate. Training teachers on the use of the materials should be at top of the list of professional development offerings. In summary, just as Ms. Monica stated, "We, as a society, need to think about how to better prepare our middle school and high school teachers to teach ELLs how to read."

\section{Being the Agents of Professional Development}

YOU need to reach out for the support.

Ms. Monica

Ms. Monica believes that teachers should take the initiative in their professional development. She perceives professional development as a matter of "networking" in some sense, "knowing whom you can call and ask for help to understand what you don't understand” (Ms. Monica). Teachers all encounter problems, dilemmas, and situations where they need help. Such networking allows them to dialogue with other professionals, get to learn different perspectives, and work as a team to accomplish more successes.

In this process, teachers themselves should be the agents of their professional development.

It really depends on how open-minded you are- - how willing you are to work to get the support. Some people don't want to learn and are just stubborn, so you don't get any support because you feel you know it all. Sometimes people work too hard because they concentrate on figuring it out for themselves when you could have easily come up with the same solution with half the time if you seek for support. Therefore, the support is as much as you want it or as least as you want it. (Ms. Monica)

Usually, the "best practices" and "research-based programs" are mandated from the outside, and they are less powerful, less meaningful, and less sustainable than those that are initiated and valued by teachers themselves. Instead of being passive receivers of professional development, teachers should be active constructors, taking ownership of their personal professional accountability, rebuilding what is told to them into something they feel more relevant, meaningful, and suitable for their classrooms, for their teaching to make a real difference in students' learning outcomes (Wei, 2016). A didactic mode of professional development is not effective in facilitating authentic professional learning among teachers (Webster-Wright, 2009). Teachers should be empowered to start negotiating their roles and responsibilities in teacher professional development.

\section{Concluding Remarks}

The unprecedentedly growing number of students who are linguistically and culturally diverse has posed an immense challenge to American education. All students, regardless of their home language, race, ethnicity, and cultural origin, are entitled to equal educational opportunities. A high-quality education for these students requires special knowledge and skills of teachers. Professional development is vital for teachers in enhancing their knowledge and skills and being better able to meet the language and academic needs of ELLs (Vogt, 2009).

Successful professional development for teaching ELLs should emphasize locally devised, context-specific solutions, active teacher participation in the program; coherence and teacher commitment to long, sustainable change; and creating activities that enable teachers to meaningfully interact with other professionals. Teacher development cannot maximize its influence until it truly engages teachers in growing up as reflective teachers. Iddings and Rose (2012) argued that "one size fits all" pedagogy and teacher development does not work 
effectively. The most effective teacher professional development should be in no way prescribed by the providers. Instead, it should feature respect for recipients' voice and feedback, and a dialogic nature of collaboration between the recipients and the providers throughout the program.

This paper provides an in-depth exploration of a newcomer middle school principal's professional development experiences and perspectives. Through reflecting on her professional development experiences and narrating her personal practical knowledge in action, this study has provided some practical considerations in designing and enacting ELL teacher professional development. It will help teacher educators, trainers, and school administrators to unravel how educators' experiences of professional development can influence their knowledge and practices. What distinguishes this study from most of the others about teacher professional development is its rich description of the participant's experiences and the illumination of the participant's perspectives. More often than not, teacher professional development focuses on the "best practices" and "research-based programs," but provides little input from the recipients about their experiences and perspectives. This study strives to break this prevalent model of professional development by gearing towards how an educator perceives the problems in teacher professional development for ELLs and how to best address the problems. Hopefully, this study will shed important light on how to construct positive professional development that benefits teachers and ELL students both theoretically and practically.

\section{References}

Beninghof, A., \& Leensvaart, M. (2016). Co-teaching to support ELLs. Educational Leadership, 73(5), 70-73.

Bruner, J. (1985). Narrative and paradigmatic modes of thought. In E. Eisner (Eds.), Learning and teaching the ways of knowing (pp. 97-115). Chicago: University of Chicago Press.

Bruner, J. (1996). The culture of education. Cambridge, Massachusetts: Harvard University Press.

Choi, D. S., \& Morrison, P. (2014). Learning to get it right: Understanding change processes in professional development for teachers of English learners. Professional Development in Education, 40(3), 416-435. https://doi.org/10.1080/19415257.2013.806948

Chomsky, N. (1965). Aspects of the theory of syntax. Cambridge, MA: MIT Press. https://doi.org/10.21236/AD0616323

Clair, N., \& Adger, C. T. (2010). Sustainable strategies for professional development in education reform. In K. Johnson (Eds.), Teacher Education (pp. 29-50). Alexandria, VA: Teachers of English to Speakers of Other Language.

Clandinin, D. J., \& Connelly, F. M. (2000). Narrative inquiry: Experience and story in qualitative research. San Francisco: Jossey-Bass.

Clandinin, D. J., Pushor, D., \& Orr, A. M. (2007). Navigating sites for narrative inquiry. Journal of Teacher Education, 58(1), 21-35. https://doi.org/10.1177/0022487106296218

Coleman, R., \& Goldenberg, C. (2009). What does research say about effective practices for English learners? Kappa Delta Pi Record, 46(1), 10-16. https://doi.org/10.1080/00228958.2009.10516683

Connelly, F. M., \& Clandinin, D. J. (1990). Stories of experience and narrative inquiry. Educational Researcher, 19(5), 2-14. https://doi.org/10.3102/0013189X019005002

Connelly, F. M., \& Clandinin, D. J. (2006). Narrative inquiry. In J. L. Green, G. Camilli, \& P. Elmore (Eds.), Handbook of complementary methods in education research (pp. 477-487). Mahwah, NJ: Lawrence Erlbaum.

DelliCarpini, M., \& Gulla, A. N. (2009). Success with ELLs: Creating space for collaboration. English Journal, 98(4), 133-137.

Echevarria, J., Short, D., \& Powers, K. (2008). Making content comprehensible for non-native speakers of English: The SIOP model. International Journal of Learning, 14(11), 41-49. https://doi.org/10.18848/1447-9494/CGP/v14i11/45514

Franco-Fuenmayor, S. E. (2013). Examining dual language, bilingual, and ESL teachers' knowledge, professional development experiences, and perceptions about second language programs in Texas. Unpublished doctoral dissertation, Texas A \& M University.

Guskey, T. R. (2000). Evaluating professional development. Thousand Oaks, CA: Corwin Press.

Honigsfeld, A., \& Cohan, A. (2008). The power of two: Lesson study and SIOP help teachers instruct ELLs. Journal of Staff Development, 29(1), 24-26. 
Iddings, A. D., \& Rose, B. C. (2012). Developing pedagogical practices for English Language Learners: A design-based approach. Pedagogies: An International Journal, $7(1), \quad 32-51$. https://doi.org/10.1080/1554480X.2012.630510

Lyons, N., \& LaBoskey, V. K. (2002). Why narrative inquiry or exemplars for a scholarship of teaching? In N. Lyons \& V. K. LaBoskey (Eds.), Narrative inquiry in practice: dvancing the knowledge of teaching (pp. 11-27). New York: Teachers College Press.

Maxwell, L. A. (2011). Teachers urged to listen to ELL students. Education Week, 31(12). Retrieved from https://www.edweek.org/ew/articles/2011/11/16/12brief-b1.h31.html

Mensah, F. (2013). Theoretically and practically speaking, what is needed in diversity and equity in science teaching and learning? Theory into Practice, 52(1), 66-72. https://doi.org/10.1080/00405841.2013.743781

Molle, D. (2013). Facilitating professional development for teachers of English language learners. Teaching and Teacher Education, 29(1), 197-207. https://doi.org/10.1016/j.tate.2012.10.002

Ramirez, P. C., Gonzales-Galindo, D., \& Roy, B. (2016). Preparing pre-service secondary teachers in Arizona: Using culturally responsive approaches to learn from diverse secondary English learners. Multicultural Education, 23(2), 22-30.

Short, D. (2013). Training and sustaining effective teachers of Sheltered Instruction. Theory into Practice, 52(2), 118-127. https://doi.org/10.1080/00405841.2013.770329

Short, D. J., Echevarria, J., \& Richards-Tutor, C. (2011). Research on academic literacy development in sheltered instruction classrooms. Language Teaching Research, 15(3), 363-380. https://doi.org/10.1177/1362168811401155

Smith, S. U. (2014). Frameworks shaping an online professional development program for K-12 teachers of ELLs: Toward supporting the sharing of ideas for empowering classroom teachers online. TESOL Journal, 5(3), 444-464. https://doi.org/10.1002/tesj.154

Tarone, E., \& Allwright, D. (2005). Second language teacher learning and student second language learning: Shaping the knowledge base. In D. Tedick (Eds.), Second language teacher education: International perspectives (pp. 5-23). Mahwah, NJ: Lawrence Erlbaum.

Teemant, A. (2014). A mixed-methods investigation of instructional coaching for teachers of diverse learners. Urban Education, 49(5), 574-604. https://doi.org/10.1177/0042085913481362

Texas Education Agency. (2007). Texas A \& M University system's support activities related to the limited English proficient student success initiative. Southwest Educational Development Laboratory.

Texas Education Agency. (2020). 2020-2021 Teacher Shortage Areas and Loan Forgiveness Programs. Retrieved from https://tea.texas.gov/sites/default/files/TAA_teacher_shortage_vF.pdf

Vogt, M. (2009). Teachers of English learners: Issues of preparation and professional development. College Reading Association Yearbook, 30, 23-36.

Walqui, A. (2006). Scaffolding instruction for English language learners: A conceptual framework. International Journal of Bilingual Education and Bilingualism, 9(2), 159-180. https://doi.org/10.1080/13670050608668639

Webster-Wright, A. (2009). Reframing professional development through understanding authentic professional learning. Review of Educational Research, 79(2), 702-739. https://doi.org/10.3102/0034654308330970

Wei, L. (2016). Unpacking tensions: An autobiographical narrative inquiry into the cross-cultural teaching journey of a TESOL teacher educator. In Haworth, P., \& C. Craig (Eds.), The career trajectories of English language teachers (pp. 25-38). Oxford, UK: Oxford Studies in Comparative Education.

Welsh, L. C., \& Newman, K. L. (2010). Becoming a content-ESL teacher: A dialogic journey of a science teacher and teacher educator. Theory into Practice, 49(2), 137-144. https://doi.org/10.1080/00405841003641485

Zehr, M. A. (2011). Bringing context to ELL instruction. Education Week, 4(2), 5.

\section{Copyrights}

Copyright for this article is retained by the author(s), with first publication rights granted to the journal.

This is an open-access article distributed under the terms and conditions of the Creative Commons Attribution license (http://creativecommons.org/licenses/by/4.0/). 